\title{
Knowledge management and its application in human resources management in the context of globalization
}

\author{
Olga Ponisciakova, ${ }^{1, *}$ \\ ${ }^{1}$ University of Zilina, Univerzitna 1, 010 26, Zilina, Slovak Republic
}

\begin{abstract}
Business management is a set of specific activities that a daily manager performs. Many facts and their course are influenced by their intuitive or cognitive decision-making. It has the ability to manage traditionally, dogmatically, or innovatively, which also depends largely on its personality profile. However, all executives jointly influence the environment in which they can apply their skills. It is an environment that is changing globalization. Managers need to recognize and interact with their impacts if they want to manage competitive businesses. They are looking for ways to reveal and use the dynamics and complexity of the predominantly variable business environment. In doing so, they use a variety of progressive management support tools that evolve as a reflection of environmental variability and turbulence. One of the options offered for more effective management is knowledge management. This form of management is an effective and efficient acquisition, creation and sharing of knowledge in all their manifestations and forms within and around the enterprise. Knowledge management is based on the principles of a holistic, systematic approach to data management and processing for the purpose of sustainable business development. In order to fulfill this ambition, however, the decisive factor is, above all, the level of knowledge participation based on the creation of new values as well as wealth itself. The paper highlights the importance, mission and functionality of knowledge management in human resource management, with a great deal of knowledge, given the importance of corporate assets at the forefront, presents and evaluates the results of the knowledge management survey in the selected company in the Slovak Republic.
\end{abstract}

\section{Introduction}

At the present time of globalization, which is characterized by high dynamics of continuous change, the notions of competitiveness and productivity resonate in assessing the success of businesses. As the autors [1] claim: „Enterprises (regardless of size, hence small and medium sized including), in order to flourish and stay competitive in the future, have to face and properly address current challenges of market economy. To address them properly, means to adapt and adjust to changeable market conditions, e.g. they can and use

* Corresponding author: olga.ponisciakova@fpedas.uniza.sk 
20th century business management in conditions of 21 st century. One of essential changes in market economy is the new system of creation of welfare and wealth of both enterprises and countries that is the knowledge economy". Business competitiveness depends to a large extent on how businesses can respond to globalization itself, with pressure to increase competition from both developed and some developing countries, as well as to a permanent and rapid change not only in technology but also in markets, trends and business models and, last but not least, chronic economic and political instability that affects energy supply, migration trends, the wider economic environment and the European Union's geopolitical role, including competition between different economic and social models. To remain competitive, it is essential to constantly find ways to improve the use of all business resources - people, machines, materials, information and other inputs. Their finding is at the core of the activities of managers who, with their qualified decisions, can contribute to the development of the company. For the right decisions, it is necessary to have the necessary information and knowledge. People are the most important resource in a business and their education is a fundamental category of sustainable growth. The ability of workers to use their acquired knowledge in their daily work enables them to react flexibly and quickly to emerging situations and to address them immediately with regard to business efficiency. Depending on the constant changes that are being made today, it is necessary to adapt knowledge and skills to current requirements.

Knowledge management helps business management to respond to present-day processes through lifelong learning and make decisions about the future based on knowledge of the past and the ability to analyze future developments. Knowledge becomes the most important form of capital of a modern enterprise. In spite of the fact, as the authors [2] point out: „The use of knowledge management in the context of sustainability has been increasingly important over the years. Despite this importance, it is observed that this area is still little explored and there are many possibilities of academic research". The authors [3] also support this: ,... that there are four main knowledge gaps in this area. First, there are moral dilemmas created by boundary shifts, arising from the development of quasimarkets. Second, the phenomenon of "tactical mimicry" represents a key theoretical platform not yet fully explored. Third, the lack of clear, comparative assessments of social enterprises across quasi-markets, and other types of service providers is also apparent despite offering a significant methodological opportunity for scholars. Fourth, there is the issue of how social enterprises engage in and resource the operational functions that will support their management of conflicting logics, especially rigorous impact measurement. "They are all employees of the company actively involved in business processes. However, it is important that the importance of knowledge management should not only be emphasized on a theoretical level, but also be practical. In the context of theoretical knowledge, the paper presents findings on the use of knowledge management in business practice.

\section{Characteristics of knowledge management}

Knowledge management began to shape in the United States, and development is reflected in four development phases that replicate the development of management itself as a scientific discipline. The first is the stage of classical and neoclassical management from the late 19th and early 21 st centuries, whose founders focused on an organization which they perceived as a well-designed impersonal mechanism and did not regard human beings as a psychological-social personality, but only as a technical-economic element. This has led to social contradictions and misunderstandings. The further development of management also focused on this deficiency and the position of man in the organization changed in the connection of the technical-economic and social-psychological system. The 
second stage dates back to the 40-70s of the 20th century and is referred to as a behaviorist approach. As part of the development, it was necessary to focus on human resources themselves, as well as on their use, human resources management and proper human resources records. The third stage of knowledge management developed in the 1980s and 1990s, and knowledge management was seen as a lean management that seeks to find the most appropriate way to reduce costs while increasing product quality. Management was used as a competitive advantage and therefore had to be resistant to competition. The fourth stage developed around the beginning of the 21 st century, with globalization coming to the forefront. Businesses have crossed the borders of the country and have risen from national to international level. All the economies of the world were interconnected, corporations, mergers and communities were formed. Trade liberalization has taken place; virtual enterprises have been created in borderless capital markets. It was about interconnecting businesses, finding flexible and simpler structures, and creating and ensuring efficient logistics. $[4,5,6]$. They also point to the justification of the benefits in this era in [7] who claim that ,...managers need to implant KM, as they will enable a better understanding and awareness regarding the global dangerous impacts from unsustainable operations mainly focused on sales and cost reduction."

In the context of knowledge management, the importance of which the authors in [8] point out, it is necessary to understand the concepts of data and information correctly. These are essential for defining the most important concept of knowledge.

Data (data) are expressed as symbols (letters, text, sound, image), but it can also be sensory sensations (smell, touch). They reflect the objective reality and specific events without any link to other influences. They are all we can monitor with the senses. They are objective facts about events and exist independently of human consciousness. [9] The information includes a message, together with its content meaning for the recipient, a message that expresses a certain status. This status serves a specific goal, or induces an action. The message becomes information by human interpretation or by processing it by algorithms or by storing it in certain files. They answer the questions: who ?, what ?, when?, Where?, How ?, how much?, Why? They arise from an understanding of the relationships between data or other information, or contextualization. Information is data to which the user assigns importance and meaning to the interpretation.

Essentially, they are relevant data containing a purpose and, being bound to a human factor, are subjective in nature. In the next stage, information is raised, a personal computer is being developed, and new educational methods are being developed. The information society has guaranteed the emergence of new technologies and the transition from industrial society to the information society. $[9,10]$

Knowledge is a semantic unit formed by a system of knowledge. It is an interconnected (changeable, complementary) structure of related knowledge that can be used in interaction with the world. Knowledge of something means possessing a corresponding representation in the form of a fairly accurate and accurate cognitive model, including the ability to perform various cognitive operations with what is represented. Based on and to the extent of these operations, man (and computer) can predict and predict what must or can happen in the real world. Knowledge is the final comprehensive information with practical use, it is transformed into the level of practical application and use [9, 10] and as the autors [11] claims: „Drawing in knowledge management theory, all the organizations require a suitable knowledge management strategy to perform successfully".

\section{Knowledge management in practical application}

It is interesting to confront the whole spectrum of theoreticians' opinions on the importance of knowledge management with its practical use, not only in Slovakia but also 
in other countries. The authors in [12] claim that „Despite the acknowledged importance of knowledge management (KM), many employees avoid practicing KM at the individual level. This avoidance often leads to loss of the intellectual capital due to employee turnover Knowledge Management (KM) many employees avoid practicing KM at an individual level. This exclusion often leads to a loss of intellectual capital due to staff turnover. The authors' argument [13] is important in this context: „The process of knowledge creation, transformation, and application helps to integrate and transform big data into useful business information, thus provides an endless driving force conducive to the establishment and promotion of the core competencies of enterprises".

Greater interest in the application of knowledge management can be seen in different sectors across different countries, as exemplified by the authors in [14] who point out that ,....have developed knowledge management capabilities to address low organizational engagement (higher turnover rates) and knowledge workers' performance and, as a followup to this,."..........examine the mediation role of organizational commitment in the relationship between knowledge management practices and knowledge-worker performance“. The intermediary role of organizational commitment in the relationship between knowledge management practices and knowledge workers' performance.

\section{Methods}

In the following part, we will focus on the research of knowledge management in the selected company in the conditions of the Slovak Republic. This was realized by the method of inquiry, in the form of a questionnaire and the results were processed by the method of analysis and synthesis. Employees, mostly male (63\%) aged 25-45 (56\%), mostly working in the company for more than 5 years (38\%) participated in the survey.

\section{Results}

Their awareness of knowledge management is satisfactory, as confirmed by $41.18 \%$ of the positive answers to the question of whether they know what knowledge management is. In answering the question of whether they are using knowledge, information and data in their workload, $36.76 \%$ of respondents confirmed a positive answer to their daily workload. It was interesting to find out that up to $30.88 \%$ of respondents consider using knowledge management in the company as insufficient. Positive cognitive attitude to the question „Do you consider knowledge management to be necessary in society?“ expressed by $57.35 \%$ of respondents. Positive impacts from the use of knowledge management in the company in relation to the competition were not confirmed by employees and $38.24 \%$ said that knowledge and their use are rather not a competitive advantage. Questions „Do you know what the SAP PLM system is?“ and „Are you familiar with the new SAP PLM system?“ they are closely linked and the answers also confirm this fact. $90 \%$ of the respondents know the terms and $95.59 \%$ are familiar with them. Next question Are you identified with the new SAP PLM system? and the most numerous response was rather than $39.71 \%$, probably because of the habit of the old computer system, and there was a problem getting used to the new system. $61.76 \%$ of respondents (regardless of whether they are executive or managerial) said they were using the PLM system SAP. The survey also showed that $42.65 \%$ of respondents think they have a good command of the PLM system SAP. When asked whether the PLM SAP system has the most numerous answer - 57.35\% - the answer was yes: the SAP system has advantages. On the contrary, to the question Does the PLM have SAP disadvantages? therefore, the most numerous response was $45.59 \%$. Question Do you think that the implementation of the PLM system has made work more efficient? was 
answered positively - 48, 53\% of respondents. Rather, what constitutes $51.47 \%$ of the answers reflects the question "Do you think that knowledge management in the company is of a sufficient standard?" Respondents to the question "Would you change the established SAP program to another or the original one used in the company?" responded most negatively $-44.12 \%$.

\section{Discussions}

Utilization and evaluation of knowledge, their continuous development is crucial for the selected society. The importance is decisive especially in terms of further new development of society. The company is able to gain a competitive advantage by good and quality knowledge management and above all to maintain this competitive advantage for a very long time. Other forms in society such as technology, products, sales and all the activities of the company come under the strong subordination of knowledge management. The company has significantly changed its priorities in terms of need and, above all, the importance of individual forms of capital. The company is well aware of what it can gain from quality knowledge management and has therefore been actively paying attention to it recently. Knowledge management in the PLM system could have a better level than it currently has, even though the company has problems that still exist in the company with the implementation of the new system, especially by getting used to the new system. However, the introduction and improvement of the new system is in its infancy. The company still has a long way to improve, as long as knowledge management is at the same level as planned when implementing the new strategy, the strategy to focus on knowledge management. The knowledge survey carried out among employees assessed the level of knowledge management in the company as insufficient. On the other hand, employees are satisfied with the new system in place despite the finding that the level of knowledge management is not sufficient. Employees adapt to the new system and try their best to work in SAP, to communicate with IT managers and technicians to correct errors and help improve the new program. Despite the problems encountered in getting used to the new PLM system, employees would no longer want to return to the original program that the company has been using for years. In the area of knowledge management, the company should focus more on achieving a shortening of the product development cycle, as this will guarantee the company a competitive advantage. Indeed, shortening the product development cycle will allow you to be different, to be fast, to be at the forefront of competition. Guaranteed innovation and development of new products will make the company prosper. The company must also improve in the area of innovation management and organizational learning. In particular, investments will guarantee the new development of the company in the field of knowledge management. Another possibility to increase the level of knowledge management is to invest in the dissemination of expertise to all employees and people throughout the company. The company must interconnect the network between all internal and external entities, which will facilitate communication between these entities, making it easier to order goods, from quicker order processing to delivery to the final consumer. The company should ensure that all employees receive the insights and ideas that are needed for their daily work. Another possibility to increase knowledge management is to solve all problems related to information and data, even those intractable or threatening. The company should ensure the management of the intellectual capital and intellectual assets of workers, such as know-how from their own employees in the company. The company must focus more on its employees who use knowledge in their work and, above all, it should communicate more with them. Employees who work with the system on a daily basis know what deficiencies the SAP system has, but are not able to remedy them, they only recommend what and how it could work better. Therefore, 
communication is needed between employees and IT managers who are trying to improve the program and try to eliminate the deficiencies that the program is supposed to eliminate and remove. More frequent meetings and more regular training will ensure effective improvement of the level of knowledge, on the one hand in terms of good program control and on the other hand, remedying the shortcomings. It is therefore necessary to remedy any internal weaknesses in the system that employees use every day. It is necessary to eliminate the problem of lengthy loading of information into text documents, which employees can then print and put into their folders. Another drawback of the system that needs to be eliminated is easier interconnection between all warehouses, so as to guarantee the up-todate status of the products of each warehouse, e.g. if one warehouse needs a certain volume of products that it does not have but has another warehouse. The system in place should be a double backup of data, not just one server. The system should be easier to use, especially for most employees who need perhaps half the data for their work. Certainly there could be fewer icons, as some are still not used. It would certainly make it easier for all employees to work as well as lengthy data retrieval by dividing the program by work level itself, top management or managers. Increasing the level of knowledge management can also be ensured by the participation of managers at various knowledge management conferences. Executives have the opportunity to participate in these conferences and trainings where they can learn to work with knowledge and how to use them more effectively. Indeed, the growing content of knowledge is made available to develop and ensure the creation of products and services. The company should also use association rules as a data mining technique. This data mining is dedicated to the process of acquiring new knowledge from large amounts of data. Association rule techniques are applicable to narrower external systems as well as to more general knowledge-based systems. Association rules as a data mining technique are applicable in a variety of applications such as shopping cart analysis, discovering hidden item dependencies, or referrals. The company has the potential to improve the quality and level of knowledge management based on recommendations. [15]

Knowledge management is considered to be one of the decisive factors for the successful functioning of economic entities. It is one of the new perspectives on organization management. On the one hand, it has its supporters and, on the other, its opponents.

The actual process of transforming information into knowledge takes place within the functioning of the whole organization, it is not enough in one department or department. The process of turning information into knowledge is primarily a process of maximizing the value of an organization. However, it is essential to be aware of the fundamental difference between information and knowledge. Especially the difference is that information is an input into the knowledge process itself where coordination of all activities is needed. All knowledge that is not applicable and which is not used will remain information until it is transformed into a value creation process.

The acknowledgements: Sustainable human resource management in the era of globalization ' 4 / PEDAS / 2019

\section{References}

1. I. Litvaj, D. Stancekova, Decision - Making, and Their Relation to The Knowledge Management, Use of Knowledge Management in Decision - Making. Procedia Economics and Finance 23, 467-472 (2015)

2. V. W. B. Martins, I. S.Rampasso, R. Anholon, O. L. G. Quelhas, W. Leal Filho, Knowledge management in the context of sustainability: Literature review and opportunities for future research. Journal of cleaner production 229, 489-500 (2019) 
3. CH. Mason, M. J. Roy, G. Carey, Social enterprises in quasi-markets: exploring the critical knowledge gaps. Social enterprise journal 15, 358-375 (2019)

4. M. M. Capozzi, Knowledge Management Architectures Beyond Technology. First Monday 12 (2007). Avaliable at: http://firstmonday.org/htbin/cgiwrap/bin/ ojs/index.php/fm/article/view/1871/1754

5. CH. Collins, G. Parcel, Knowledge management. (Computer Press, Czech Republic, 2005)

6. P. Drucker, Budoucnost uz nastala. Moderni rizeni 3, (1998)

7. G. C. Lopez-Torres, J. A. Garza-Reyes, G. Maldonado-Guzman, V. Kumar, L. RochaLona, A. Cherrafi, Knowledge management for sustainability in operations. Production planning \& control 30, 10-12 (2019)

8. K. Rosendal, J.B. Skjaerseth, A. Steinar, Knowledge-based management of protected areas and hydropower: the case of Norway. International enviromental agreementspolitics law and economics 19, 4-5 (2019)

9. T.H. Davenport, Enterprise 2.0: The New, New Knowledge Management?, Harvard Business review (2008). Avaliable at: http://discussionleader.hbsp.com/ davenport/2008/02/enterprise_20_the_new_new_know_1.html.

10. K. Dalkir, Knowledge management in theory and practise. (Elsiever Butterworth Heinamann, UK, 2005)

11. S.S. Hosseini, Y.N. Tekmedash, A.Karami, Y. Jabarzadeh, The Impact of Knowledge Management Strategy on Service Innovation Performance in Private and Public Hospitals. Iranian journal of management studies 12, 1-24 (2019)

12. S. Shamim, S. Cang, H. Yu, Impact of knowledge oriented leadership on knowledge management behaviour through employee work attitudes. International journal of human resource management 30, 2387-2417 (2019)

13. X. M. Yin, J. Chen, C. Zhao, Double Screen Innovation: Building Sustainable Core Competence through Knowledge Management. Sustainability 11, (2019)

14. S. Razzaq, M. Shujahat, S. Hussain, F. Nawaz, M. Wang, M. Ali, S. Tehseen, Knowledge management, organizational commitment and knowledge-worker performance The neglected role of knowledge management in the public sector. Business process management journal 25, 923-947 (2019)

15. V. Havrilova, Znalostny manazment v spolocnosti Kofola, a.s. (EDIS, Zilina, 2014) 